\title{
Problemas de la comunicación literaria. Del sueño de la comunicación al diálogo de sordos
}

\author{
Dr. Nicolás Garayalde', Universidad Nacional de Córdoba, \\ Argentina - CONICET \\ Recibido: $\quad 17$ de setiembre, 2018. \\ Aceptado: $\quad 4$ de abril, 2019.
}

\section{Resumen}

Este artículo analiza la noción de "comunicación literaria" considerando viejas, pero aún vigentes preguntas a la luz de nuevos aportes críticos. ¿Qué problemas plantea la especificidad de la comunicación literaria? ¿Es el malentendido una condición inevitable de la comunicación literaria? ¿Cómo se comunica un texto escrito con el lector? ¿Cómo es el lector capaz de comunicar su lectura? ¿Qué consecuencias tiene para la crítica literaria? Para trabajar este problema, se trabajarán los siguientes conceptos: el sueño de la comunicación (Richards, 1976), el diálogo ininterrumpido (Gadamer, 1989 y 2004 y Derrida, 1972, 1979, 1989, 1997 y 2003) y el diálogo de sordos (Bayard, 2002). El enfoque será sobre todo, en el crítico contemporáneo Bayard para pensar el malentendido como fundamento de la comunicación.

\section{Issues in literary communication: From the dream of communication to a dialog of the deaf}

\section{Abstract}

This article analyzes the notion of literary communication considering old but still valid questions in light of new critical contributions. What problems does the specificity of literary communication pose? Is misunderstanding an inevitable condition of literary communication? How does a written text communicate with the reader? How is the reader able to communicate his reading? What are the consequences regarding literary criticism? To work on this problem, we will follow a path that will halt at the following stops: the dream of communication (Richards), the uninterrupted dialogue (Gadamer and Derrida), and the dialogue of the deaf (Bayard). We will focus especially on the contemporary critic P. Bayard to think of misunderstanding as the basis of communication.

1 El Dr. Nicolás Garayalde es Doctor en Letras por la Universidad Nacional de Córdoba, Argentina. Labora como profesor asistente de la cátedra de Teoría Literaria de la Facultad de Filosofía y Humanidades, en la Universidad Nacional de Córdoba, Argentina. Además, es becario posdoctoral de la agencia CONICET, en Argentina. Contacto: negarayalde@gmail. com.
Nicolás Garayalde. Problemas de la comunicación literaria. Del sueño de la comunicación al diálogo de sordos. Revista Comunicación. Año 40, volumen 28, número 1, enero-junio, 2019. Instituto Tecnológico de Costa Rica. ISSN: 0379-3974 I e-ISSN1659-3820.

\section{PALABRAS CLAVE:}

comunicación - diálogo - malentendido - lectura - crítica literaria - psicoanálisis deconstrucción - teoría literaria.

\section{KEY WORDS:}

communication - dialogue misunderstanding - reading - literary criticism - psychoanalysis - deconstruction - literary theory. 
Problemas de la comunicación literaria. Del sueño de la comunicación al diálogo de sordos

\section{INTRODUCCIÓN}

Pocos personajes de la literatura ostentan el poder analítico de Auguste Dupin. De ello da cuenta un particular episodio -sorprendente, caricaturesco, irónico tal vez- que se encuentra hacia el inicio de The Murders in the Rue Morgue (2007). El narrador, que ha entablado durante su residencia en París una amistad con el agudo detective, narra que una noche, durante sus habituales caminatas, Dupin interrumpe un extenso silencio de quince minutos con un comentario sorprendente: "Tienes razón. Es un individuo muy pequeño, y tendría más éxito si actuase en obras más livianas". Sorprendente porque adivina $-\mathrm{o}$ bien: interpreta- el pensamiento que en ese preciso instante ocupa la mente de su amigo: “¿Cómo es posible que hayas sabido lo que estaba pensando de Chantilly?" (2006, p. 8), interroga inquieto el narrador. La respuesta no tarda en llegar: Dupin ha observado cada gesto de su compañero desde el momento en que, quince minutos atrás, tropezaron con un vendedor de frutas. Una mueca, la dirección de la mirada, un gesto de fastidio, una ligera sonrisa, una recomposición en la postura corporal: el seguimiento de esos indicios permite a Dupin trazar el curso de los pensamientos de su silencioso camarada, experimentando el mismo estado mental que le permite introducir su palabra en un diálogo en el que hasta entonces no se ha proferido ninguna.

El episodio escenifica una fantasía de comunicación, el sueño de una crítica literaria, tal como era pensada en Principles of Literary Criticism de I. A. Richards (1976):

Comenzamos desde el natural aislamiento y separación de las mentes. (...) La comunicación tiene lugar cuando una mente actúa sobre su entorno y este influencia otra mente, de tal modo que en ésta última ocurre una experiencia que es como la experiencia de la primera mente, y es causada en parte por esa experiencia (1976, p. 137).

A esta fantasía de un lector-Dupin, sueño, como diría Geoffrey Hartman (1975), de una "comunicación total y controlable" (p. 23), se opone otra menos ambiciosa, ligada a la hermenéutica, que imagina un diálogo en el que la comunicación se establece a partir de tres instancias -el autor, el texto y el lector-, don- de la obra emerge como resultado de una dialéctica en la que convergen los tres mundos. Se trata de una particular fusión de horizontes en la que, a pesar de las distancias, la comunicación es posible. Esta amable concepción, que busca congeniar las dificultades epistemológicas de la distancia espacial y temporal propias de la lectura de obras literarias, encuentra un notable referente en Hans-Georg Gadamer, infatigable buscador de un diálogo posible y respetuoso de las limitaciones epistemológicas que imponen las particularidades de la comunicación diferida entre el autor, el texto y el lector.

Más allá de este lector-hermenéutico, punto medio entre el anhelo de una comunicación total y el reconocimiento de los obstáculos insuperables de la comunicación literaria, se encontraría una posición más radicalizada, efecto de una situación teórica que se construye en el entramado de las perspectivas deconstruccionistas -fundamentalmente la posición de Jacques Derrida frente a Gadamer-y aquellas focalizadas en el lector de corte psicoanalítico. Atento tanto a las dificultades propias de la condición retórica del texto como al rol del lector en la configuración de la obra, un crítico contemporáneo como el psicoanalista Pierre Bayard (1954- ) parece ubicar la experiencia de la lectura más cerca de la sordera que de la comunión.

¿Es posible un lector-Dupin? ¿Supone la labor del crítico el despeje de las perturbaciones que afectan la comunicación? ¿Son la ambigüedad y el malentendido una condición inevitable de la comunicación literaria? ¿Qué problemas plantea la especificidad de la comunicación literaria? ¿Cómo se comunica un texto escrito con el lector? ¿Cómo es el lector capaz de comunicar su lectura? ¿Qué consecuencias tiene para el ejercicio de la crítica? Estas preguntas motivan el siguiente artículo, que pretende detenerse en el pensamiento de críticos contemporáneos -particularmente en Bayard- para repensar un problema que ha atravesado la historia de la teoría literaria: la comunicación.

Para trabajar este problema, transitaremos un camino -cuyo humilde y apenas visible guía será Anatole France (1924)- que se detendrá en las siguientes paradas: el sueño de la comunicación (Richards), el diálogo ininterrumpido (Gadamer-Derrida) y el diálogo 
de sordos (Bayard). Este camino nos conducirá de un sueño a otro: de la comunicación a la participación, de la imitación a la creación.

\section{EL SUEÑO DE LA COMUNICACIÓN}

¿Qué no daríamos para ver durante un minuto el cielo y la tierra con el ojo facetado de una mosca, o para comprender la naturaleza con el cerebro rudo y simple de un orangután?

Anatole France

El sueño de una comunicación total y controlable es antiguo en la teoría literaria y se ha ligado con frecuencia a la paternidad del autor. En el Fedro, Platón argumentaba que "si un escrito se ve insultado o despreciado injustamente, tiene siempre necesidad del socorro de su padre; porque por sí mismo es incapaz de rechazar los ataques y de defenderse" (1955, p. 184). Digamos que esta defensa no se remite solo a las objeciones que el escrito pueda enfrentar; supone defenderse también del malentendido. Es decir, de la injusticia de su lectura. Pero, ¿qué es una lectura justa? En la crítica que ha creído ver en las condiciones de producción de la obra la fuente legítima de su interpretación -es decir, principalmente, en el positivismo biográfico de críticos como Charles-Augustin Sainte-Beuve o Gustave Lanson-, la justeza de una interpretación radicaba en la capacidad, propia de un lector-Dupin, de identificar sea la intención del autor, sean las fuerzas sociales que dieron nacimiento a la obra. La dificultad mayor en la comunicación literaria residía en las perturbaciones de la distancia histórica, social o cultural que separan el autor y su texto del lector. Por ello, el sueño de la comunicación radica en la posibilidad de sortear estos ruidos comunicativos, meros obstáculos a la buena lectura que la labor histórica y filológica buscará despejar.

Pero aun apartado el autor (su vida, su psicología y su época) del centro de la escena, en una precoz close reading que anunciaba la gestación del New Criticism, I. A. Richards (1976) anhelaba todavía la posibilidad de experimentar una comunicación total y controlable, libre de las perturbaciones que afectan la transmisión del significado. O más bien, para el caso, de la experiencia: es decir, el modo en que la mente es afectada por aquello que lee. Formado en la psicología conductista, la concepción de la experiencia estética que fundamenta la crítica de Richards habilita una curiosa paradoja: aun cuando se trata de una crítica psicológica, el interés se deposita exclusivamente en el texto; aun cuando se trata de una crítica textualista, el texto es inexistente objetivamente, reducido a un mero estímulo que, bien empleado, es capaz de comunicar una experiencia ${ }^{2}$. Posibilidad que se asienta en la concepción del lenguaje como un medio transparente para transmitir un contenido: esto es, en la coincidencia entre signo y objeto, y en la posibilidad de recuperar una experiencia alojada en el texto a través de su análisis atento.

Precisamente, De Man (2010) atacaba esta posición de Richards, heredada luego por el New Criticism, según la cual existe "una correspondencia exacta entre la experiencia originaria del autor y su expresión comunicada" (2010, p. 231). En otras palabras: la labor del crítico consistiría en re-trazar y deshacer el camino hecho por el escritor que va de la experiencia a la escritura de la obra. Como pueden ocurrir errores y producirse perturbaciones en este camino, Richards se interesa en el desarrollo de técnicas para evitarlos y llegar a buen término. Aunque manifiesta ciertas cautelas. Por un lado, desliza que "casi todas las especulaciones sobre lo que sucedió en la mente del autor son inverificables" (1976, p. 21); por otro, resigna su utopía comunicativa aceptando que las experiencias de dos mentes "en el mejor de los casos, y bajo las circunstancias más favorables, solo pueden llegar a ser similares" (p. 137). Sin embargo, resulta evidente que en la base de su perspectiva crítica se encuentra una concepción ontológica según la cual el lenguaje (poético o no) puede expresar la experiencia. En este modelo -como en aquel que se desprende del célebre esquema comunicativo de Roman Jakobson (1960)-, el ruido es un parásito por despejar.

¿Cuáles son estos ruidos que afectan la justa interpretación de un texto? Una perturbación que preocupa particularmente a Richards es la ambigüedad, a la que entiende en términos de error: "la ambigüedad

2 Tal vez allí radica la sensación que la lectura de Principles of Literary Criticism puede producir a lo largo de sus páginas: ora avatar de los pilares del New Criticism como Wimsatt y Brooks; ora avatar de la teoría del efecto de Wolfgang Iser. 
en un poema, como en cualquier tipo de comunicación, se debe a un error del poeta o del lector" (1976, p. 162). Preocupación justificada, diríamos, no tanto por los problemas metodológicos - e incluso ontológicos- que presenta al sueño de la comunicación, sino por el modo en que amenaza el valor que Richards atribuye al arte: su capacidad de organizar nuestros deseos, sintetizar orgánicamente nuestros conflictos, equilibrar los opuestos; en pocas palabras: su potencial terapéutico ${ }^{3}$.

Es notable que el alumno más importante de Richards, William Empson, se haya interesado precisamente en la ambigüedad para terminar poniendo en cuestión el modelo de su maestro. Seven Types of Ambiguity (1984) expone siete tipos de ambigüedades que impiden recrear la experiencia del autor y afectan la unidad de la obra. A diferencia de su maestro, Empson no solo muestra poco interés en la noción de unidad -sus análisis se concentran en los efectos focales de fragmentos de las obras que analiza, sin necesariamente ligarlas a un organismo mayor-, sino que pone además en jaque la posibilidad de concebir la obra literaria en tales términos. Tal es el motivo por el cual De Man ve en Empson un precursor de la deconstrucción. Al poner en evidencia el valor polisémico del lenguaje, al explorar las ambigüedades que la retórica introduce en el discurso poético, su trabajo afecta la unidad de la obra y, con ello, la posibilidad de comulgar con una experiencia del autor alojada en ella. Con Empson, la ambigüedad -y la contradicción entre sentidos resultantedeja de ser una perturbación que la labor crítica debe despejar para dar lugar a la comunicación; la ambigüedad está en el fundamento de la comunicación literaria: "las intrigas de la ambigüedad están entre las raíces mismas de la poesía" $\left(1984\right.$, p. 3) ${ }^{4}$. Con la séptima ambigüedad, la unidad literaria se ve fragmentada y la comunicación como una apropiación por parte del receptor de una experiencia autoral encuentra un obstáculo epistemológico insoslayable: el texto contiene no solo significaciones diferentes, sino además excluyentes entre sí, más allá de la voluntad del autor.

La forma-objeto con la que Richards (1976) piensa la poesía ya no puede ser concebida como el depósito de una experiencia del autor que es luego estimulada en el receptor. Frente a esta argumentación, De Man señalaba que, por el mero hecho de llevar a cabo la construcción de una forma, el estatus de la existencia de ese objeto queda cuestionado: "en lugar de contener o reflejar la experiencia, el lenguaje la

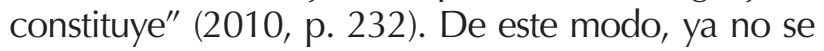
trataría de una teoría de la forma significante sino de la forma constituyente. La tarea no sería descubrir la experiencia a la que hace referencia la forma sino cómo esta última construye una experiencia: "ya no es una cuestión de imitación sino de creación -dice Paul de Man-; ya no de comunicación sino de participación" (p. 232).

Así establecido el panorama, la lectura atenta, filológica, no parece resolver el problema mayor que aquejó a la hermenéutica desde sus comienzos: la distancia (histórica y cultural) entre el autor, el texto y el lector. ¿Qué queda entonces de la comunicación literaria si en sus raíces y su fundamento se aloja la ambigüedad y la contradicción que opera la retórica? ¿Qué se puede esperar de la literatura si se resigna la utopía de un comulgar con la experiencia del autor que nos conduzca al valor terapéutico pretendida

3 A partir de la diferencia que Richards establece entre "enunciados referenciales" (propios del discurso científico) y "enunciados emotivos" (propios del discurso literario), la pregunta por el valor de la literatura se responde según su valor terapéutico.

4 Si bien en este ensayo no nos detendremos en la semiología de Umberto Eco, es importante destacar que la concepción de "obra abierta" que desarrolla en 1962 está fuertemente articulada a la noción de ambigüedad: "la obra de arte -dice Eco- es un mensaje fundamentalmente ambiguo, una pluralidad de significados que conviven en un solo significante" (1992, p. 34). Lejos aún de Los límites de la interpretación (1990) -en el que un Eco más conservador recula ante la estocada deconstruccionista y la radicalidad de algunas teorías de la lectura-, Obra abierta se presenta por momentos como una suerte de apología a la ambigüedad, a la que concibe como el verdadero fundamento del acontecer artístico contemporáneo: "la obra permanece inagotable y abierta en cuanto ambigua, puesto que se ha sustituido un mundo ordenado de acuerdo con leyes universalmente reconocidas por un mundo fundado en la ambigüedad" (p. 80). Aún más, apoyado en la teoría de la información, Eco valora la novedad comunicativa de la obra de arte según su grado de imprevisibilidad: cuanto más comprensible un mensaje, más previsible y trivial será; es decir, menos información podrá aportar, menos nos dirá de lo que no sabemos. Reflexionando en torno a la "poética contemporánea", Eco considera las obras de arte según el grado de previsibilidad vinculadas a la ambigüedad: "el mensaje ambiguo infunde desorden en el código" (p. 165). Cuanto mayor el desorden, mayor la información que podrán aportar, menor la trivialidad. Entre un extremo y otro, en la graduación que va de lo previsible a lo imprevisible, se juega también el riesgo de la incomunicación: "de introducirse un sistema absolutamente nuevo, el discurso se disolvería en la incomunicación" (p. 156). Pero su contrario, la comunicación total de un mensaje absolutamente comprensible, no aporta ninguna información que el receptor ya no conozca. En este sentido, en el equilibrio paradójico de una ambigüedad comunicable se cifra la posibilidad de la obra abierta. 
por Richards? ¿Qué significaría pasar de la imitación a la creación, de la comunicación a la participación? ¿Cómo salvar la comunicación, para parafrasear un título de Hartman (1981), si la lectura atenta no es capaz de resolver los inconvenientes de la ambigüedad?

\section{EL DIÁLOGO ININTERRUMPIDO}

Pero eso nos está prohibido. No podemos, como podía Tiresias, ser hombre y acordarnos de haber sido mujer.

Anatole France

La falta de inmediatez en la comunicación literaria es uno de los mayores problemas en torno al cual ha orbitado la hermenéutica contemporánea. Por ello la noción de diálogo se ha ofrecido como la vía por la cual se vuelve posible pensar la relación entre el mundo del autor, el del texto y el del lector. En este sentido, es notable el pensamiento de Hans-Georg Gadamer (1900-2002).

Para este filósofo, la hermenéutica es una vía de búsqueda de comprensión entre los hablantes. Gadamer (1989) piensa que, en contacto con otros, es posible un diálogo que lleve a una comprensión mutua, incluso a una transformación mutua, pero a condición de la buena voluntad de los hablantes, en una tradición que recuerda una expresión de Descartes: "la lectura de todos los buenos libros es como una conversación con los hombres más honestos de los siglos pasados" (1987, p. 5). En la lectura, que Gadamer piensa a partir del modelo del diálogo oral cara a cara, se trata de superar lo "extraño" del texto para que tanto el horizonte de este como el del lector se disuelvan: lo que el filósofo alemán llama la fusión de horizontes ${ }^{5}$ (Gadamer, 2004). Toda interpretación consiste en un diálogo entre el pasado y el presente. Lo que la obra nos dice depende de las preguntas que se le hacen. La comprensión tiene lugar en esa conversación en la cual el lector entra al mundo extraño del artefacto artístico y, al mismo tiempo, lo introduce en su propio universo, a través de lo cual llega a una mejor comprensión de sí mismo. Durante el diálogo pueden ocurrir desajustes y perturbaciones; pero lo que importa -y la labor del hermeneuta reside precisamente aquí- es la culminación que decanta en la comprensión: "Cuando el entendimiento parece imposible porque se hablan "lenguajes distintos" -dice Gadamer (2004)- la tarea hermenéutica no ha terminado aún. Ahí se plantea esta justamente en su pleno sentido: como la tarea de encontrar el lenguaje común" (p. 392).

¿Cómo acceder a este lenguaje que podría devolvernos -o al menos acercarnos- al sueño de la comunicación, a la comunión de experiencias? Gadamer parece dar dos respuestas a esta pregunta. En un primer momento, la respuesta se halla inmediatamente después del fragmento recién citado: "Nunca se puede negar la posibilidad de entendimiento entre seres racionales. Ni el relativismo que parece haber en la variedad de los lenguajes humanos constituye una barrera para la razón, cuya palabra es común a todos" (2004, p. 392). Buena voluntad y razón en una articulación que resonará posteriormente en Habermas (1981)- parecen sin embargo encontrar singulares dificultades frente al caso particular de la literatura. En una atenta lectura de la obra gadameriana, Vidarte interroga en este punto: "si la poesía no es un intercambio de información (...), si su verdad es tal que no admite la disquisición acerca de lo verdadero y lo falso, ¿sobre qué se articulará el acuerdo, la comprensión, la interpretación, el diálogo comunicativo?" (2006, p. 98). El propio Gadamer advierte la dificultad que plantea la literatura en un encuentro con Derrida que tuvo lugar en París en 1981. Gadamer sostiene aún la concepción de la lectura como un diálogo que se destina al acuerdo y a la unión, pero el fundamento parece no residir ya en la razón -aunque sí, aún, en la buena voluntad- sino en un "oído interior" o un "ojo interior" (1989) que se aloja en la subjetividad íntima del lector, concebido sin embargo en la estela de la fenomenología y en un marcado antipsicologismo -alérgico también a toda perspectiva psicoanalítica: "Yo diría, dejando aparte todas las diferencias de la escritura, que cada escrito, para ser comprendido, requiere una especie de tránsito al oído interno" (2004, p. 200). Oído y ojo interno, razón, buena voluntad: soportes filosóficos del fundamento de la comprensión, de la posibilidad del diálogo.

\footnotetext{
$5 \quad$ Esta noción fue luego ampliamente recuperada por la estética de la recepción alemana. Cf. Jauss (1987) e Iser (1987).
} 
La intervención de Derrida en el encuentro con Gadamer en 1981 supuso marcadas diferencias en lo referente a la posibilidad de la comunicación y el diálogo.

En primer lugar, objeta la afirmación gadameriana según la cual en un diálogo "ambos interlocutores deben tener la buena voluntad de tratar de entenderse el uno con el otro" (1989, p. 23). Para Derrida, al hacer de la voluntad la precondición del diálogo, Gadamer se inscribe en una concepción metafísica que asumiría la posibilidad de que todos sepan de manera común qué es la voluntad. Es decir, como si hubiese la posibilidad de definirla fuera de contexto, se remite a una suerte de origen y esencia. Derrida no sostiene que haya una mala comprensión absoluta, que la comunicación sea imposible. Pero, a diferencia de Gadamer, no cree que las normas mínimas de inteligibilidad sean ahistóricas y universales (es decir, no cree en un lenguaje común ligado a la razón y a la buena voluntad).

En segundo lugar, si Gadamer toma la oralidad como modelo comunicativo para pensar la escritura, Derrida invierte el esquema y trabaja con la escritura como modelo de comunicación, según una argumentación que pone en cuestión la concordancia de la palabra y el objeto ${ }^{6}$.

Esta operación había sido ya largamente desarrollada en Derrida (1972), donde se extienden los rasgos de la escritura a los demás tipos de comunicación. Entre esos rasgos se encuentran: 1) la distancia, esto es, la ausencia de un destinatario así como de un referente y por lo tanto la ruptura de una comunicación de la presencia, de un querer-decir; 2) el límite del concepto de contexto, en tanto no hay un contexto saturable que dé cuenta de manera total del signo escrito; 3) la iterabilidad del signo, es decir la capacidad de ser repetido fuera de contexto, en ausencia del emisor, del destinatario y del referente.

La hipótesis de Derrida es que estos rasgos no son específicos del concepto clásico de escritura, sino que pueden generalizarse a todo lenguaje. Toda marca, también la del lenguaje hablado, sería así un grafema en general: "la restancia no-presente de una marca diferencial separada de su pretendida producción u origen" (1972, p. 378).

Derrida extiende esta ley a todo tipo de comunicación al entender que no hay experiencia de presencia pura sino solo cadenas de marcas diferenciales. Así, la noción se ve subvertida desde la escritura, en tanto esta última está habitada por una diseminación (y no una polisemia, insiste Derrida), producto del atravesamiento del tiempo y la no saturación del contexto. La afección accidental que atentaría contra el modelo de una comunicación inmediata y transparente, mero transporte de un sentido, no sería sino la condición misma a la que aquella se sujeta en tanto el accidente está ligado a la escritura.

Aunque la hermenéutica gadameriana reconocía y prestaba atención a la mediación lingüística e histórica que ocurre en la comunicación literaria, las perturbaciones que la afectan están todavía ligadas a los ruidos de un modelo que sigue soñando con la transparencia. Con Derrida, el accidente se vuelve el fundamento de la comunicación. Ello no significa que esta no ocurra, sino que está siempre mediada por las condiciones de la escritura. Y esta última, contrariamente a lo que plantea la tradición metafísica inaugurada en Platón -a la que adhería Richards-, no es un accidente de la comunicación de la presencia, sencillamente porque toda marca está atravesada por la ausencia, la distancia y la diferencia. Fish,

6 Ricoeur (2001), aunque desde otra posición argumentativa, también había cuestionado el modelo comunicativo que Gadamer emplea para pensar la escritura a partir de la oralidad: "la relación escribir-leer no es un caso particular de la relación hablar-responder. (...) El escritor no responde al lector" (2001, p. 128). En otra oportunidad, Ricoeur planteará incluso que la hermenéutica se funda en la distancia entre la relación dialógica y la lectura: "la hermenéutica comienza donde termina el diálogo" (1995, p. 44). Tal es el motivo por el cual se ve en la necesidad de acudir al estructuralismo e introducir la explicación en el corazón de la hermenéutica, construyendo un modelo dialéctico de explicacióncomprensión: "La comprensión reclama la explicación desde que ya no existe la situación de diálogo, donde el juego de preguntas y respuestas permite verificar la interpretación en una situación a medida que se desarrolla" (2001, p. 153). A la hermenéutica dialógica, Ricoeur opondrá una hermenéutica textual que piensa la obra literaria como resultado de un proceso dialéctico que culmina en el acto de lectura. Así, la obra permanece indeterminada y sujeta a las refiguraciones de cada recontextualización. Ahora bien, a diferencia de Derrida, el énfasis está puesto en la concordancia más que en la discordancia. Esto parece advertirse particularmente en el uso que cada uno de ellos da la noción de pharmakon. Si para Ricoeur es el remedio por el cual el sentido del texto es "rescatado" (1995, p. 56), para Derrida (1997) supone por el contrario -en su lectura de Platón- el veneno que deconstruye la unidad del texto y lo disemina. En este proceso, la comprensibilidad se juega en la posibilidad de que lo refigurado aparezca ya en lo pre-figurado. Situación problemática que fuerza a Ricoeur a tratar de conciliar el estructuralismo con la estética de la recepción y lo conduce finalmente a pensar la lectura como "un drama de concordancia discordante" (2009, p. 883). 
que acuerda con Derrida en este punto, afirma de manera muy esclarecedora:

no hay diferencia entre comunicación directa y mediada porque, en un sentido fundamental, todas las comunicaciones son mediadas. Esto es, Todo tipo de comunicación se caracteriza exactamente por las mismas condiciones -la necesidad de un trabajo interpretativo, la inevitabilidad de la perspectiva y la construcción por medio de actos de interpretación de aquello que supuestamente fundamenta la interpretación, intenciones, personajes y pedazos del mundo (p. 700).

En una suerte de lógica paradójica, la comunicación ocurre en Derrida precisamente porque la mediación tiene lugar, así como la lectura es posible gracias a un margen de ilegibilidad y de indecidibilidad que se revela en cada acto interpretativo. Como en la imposibilidad de decidir que Empson desarrollaba frente a la séptima ambigüedad explorada en su libro, para Derrida la indecisión -problema irresoluble- pone en cuestión la unidad del texto, pero fundamenta también el porvenir de la lectura. Podría decirse: "en el principio era el ruido, en el principio era la interrupción":

La indecisión parece interrumpir o suspender el desciframiento de la lectura, pero en verdad asegura su futuro. La indecisión mantiene para siempre en vilo la atención, es decir, viva, despierta, vigilante, lista para tomar cualquier otro camino, para dejar que acuda, aguzando el oído, escuchándola fielmente, la otra palabra, suspendida del aliento de la otra palabra y de la palabra del otro: ahí mismo donde podría parecer aún ininteligible, inaudible, intraducible (Derrida, 2009, 35).

Estas palabras provienen de un conmovedor homenaje que Derrida rindió a Gadamer en 2003, reflexionando precisamente sobre su propio diálogo con el filósofo alemán, interrumpido tras su muerte. Pero para Derrida, este diálogo -palabra que recupera en un gesto de amistad- es ininterrumpido, precisamente, en la medida en que existe la interrupción, en la medida en que ella es "la condición para la comprensión y el entendimiento" (p. 19). ¿Cómo es esto posible? ¿Qué podrían significar estos paradójicos sintagmas que hemos anunciado más arriba ("en el principio era el ruido; en el principio era la interrupción")? ¿Qué implicancias tendrían no solo para la manera de pensar la comunicación sino también para los modos de ser de la crítica?

Lo que parece estar en juego en el debate entre Derrida y Gadamer es la relación con el otro, la relación con la alteridad. Quizás la diferencia fundamental entre sus posiciones radique en lo que pretenden escuchar del otro, en el otro. Ambos asumen la mediación (aquello que, precisamente, vuelve al diálogo un proceso sin fin); ambos apelan a una escucha del otro: Gadamer pondera la necesidad de un "oído interior"; Derrida convoca a una escucha fiel, "aguzando el oído". Pero en uno y otro la escucha apunta a lugares completamente divergentes. ¿Qué pretende oír la escucha fiel de Derrida? ¿Qué aspira a captar el oído interior de Gadamer?

Estas preguntas pueden responderse de la siguiente manera: si en Gadamer la escucha apunta a una comprensión arraigada en un lenguaje común, en Derrida apela al mantenimiento de lo que en el otro me resulta radicalmente distinto, inasimilable. Si en Gadamer la escucha apunta hacia aquello que favorece el diálogo y acerca las partes en un horizonte común, en Derrida apunta hacia aquello que entre las partes es irreductible, lo que disemina.

En el homenaje que Derrida rinde a Gadamer (2003) reflexiona sobre la interrupción provocada por la muerte de su amigo. Insiste, sin embargo, en que el diálogo entre ellos continúa, sobrevive en él, conservando al otro en el interior, cediéndole la palabra. En ese momento, Derrida hace una afirmación sorprendente y llena de sentido: el superviviente cede la palabra al amigo que ya no está "y lo hace tal vez mejor que nunca, y es esta una hipótesis aterradora. (...) La interrupción se multiplica, una interrupción afecta al otro, una interrupción en abismo, más unheimlich que nunca" (p. 18).

No es casual que Derrida evoque aquí la palabra unheimlich, que Freud (1992) exploró profusamente para designar el retorno de lo reprimido, lo familiar que se ha vuelto extraño, y que en Heidegger (2009) es utilizada en su sentido etimológico de "lo que 
no tiene hogar" ${ }^{\prime 7}$. En la evocación de esta palabra se perfila el punto por el cual se sitúa la diferencia con Gadamer: el comprender supone una fusión de horizontes a partir de la cual entre lo propio y lo extraño se regresa a casa: "cuando logramos superar los prejuicios y barreras de nuestra experiencia anterior del mundo introduciéndonos en mundos lingüísticos extraños, esto no quiere decir en modo alguno que abandonemos o neguemos nuestro propio mundo. Como viajeros, siempre volvemos a casa con nuevas experiencias" (2004, p. 92).

Para Derrida, en cambio, la comunicación no debería significar un comprender como una fusión conciliadora de horizontes. Dar lugar al otro significa la experiencia de alojarlo en su alteridad radical, en aquello que se resiste a la apropiación: "Se trata de llevar sin apropiarse. Llevar ya no quiere decir incluir, comprender en sí, sino llevarse hacia la inapropiabilidad infinita del otro" (2003, p. 71). Hay detrás de esta idea de Derrida una ética de la lectura ligada a la hospitalidad de la palabra del otro. No se trata solo de reconocer una condición ineludible de la comunicación literaria ("el ruido es el fundamento de la comunicación"); se trata también de un hacer ético en la comunicación. Ceder la palabra supone incorporarla en su alteridad, evitar la fusión con ella en una operación de fagocitación. Sin embargo, podemos encontrar una contracara de esta hospitalidad que Derrida menciona alguna vez, mucho menos presente que la anterior, y que se vincula, precisa y paradójicamente, con la apropiación. La hospitalidad en este caso está dada no del lado de la lectura sino de la escritura: una hospitalidad que en mi escritura da lugar al otro, a la apropiación de mi propia palabra:

Estoy tentado de decir que mi experiencia de la escritura me lleva a pensar que no siempre se escribe con el deseo de que a uno lo entiendan; al contrario, hay un paradójico deseo de que eso no suceda (...) si la transparencia de la inteligibilidad estuviera garantizada, destruiría el texto, demostraría que no tiene porvenir, que no rebasa el presente, que de inmediato se consume; entonces, cierta zona de desconocimiento e incomprensión es también una reserva y una posibilidad excesiva (...). Si se da a leer algo completamente inteligible, plenamente saturado de sentido, no se lo da a leer al otro. Dar de leer al otro significa también dejar desear, o dejar al otro el lugar de una intervención con la cual podrá escribir su interpretación: el otro deberá poder firmar en mi texto. $Y$ es en ese punto donde el deseo de que a uno no lo entiendan significa, simplemente, hospitalidad para la lectura del otro (2010, p. 46).

La ininterrupción del diálogo responde al carácter mediado que se opera en toda comunicación, pero se produce también en el marco de una hospitalidad doble y paradójica: la de quien cede la palabra en la escucha y la aloja en su inapropiabilidad; la de quien deja en su decir el espacio para la palabra del otro, la apropiación por parte del otro de la propia palabra. La buena voluntad -si tal cosa existe- pasa aquí no por un deseo de ser comprendido -"el que abre la boca, quiere que le comprendan; de otro modo, nadie hablaría ni escribiría", afirmaba Gadamer (1989, p. 55)-, sino por un deseo de incomprensión.

Este sorprendente deseo nos conduce al autor que nos interesará particularmente en este ensayo, en la medida en que nos permite pensar el problema de la comunicación literaria, la paradoja de la doble hospitalidad y el deseo de ser incomprendido. Nos referimos al crítico y psicoanalista francés Bayard (2002), que desde el subtítulo de uno de sus trabajos nos sitúa en el campo mismo de la paradoja y la ironía: Le dialogue de sourds.

\section{EL DIÁLOGO DE SORDOS}

Estamos encerrados en nuestra persona como en una prisión perpetua. Lo mejor que podemos hacer, me parece, es reconocer de buena gana esta espantosa condición y confesar que hablamos de nosotros mismos cada vez que no tenemos la fuerza de callarnos.

Anatole France

Como en Derrida, para Bayard la mediación y el ruido no suponen un accidente de la comunicación 
que un buen crítico debe erradicar: "el diálogo de sordos no es un accidente de la comunicación, sino su esencia" (2002, p. 184).

El diálogo de sordos es el subtítulo que Bayard da a este libro, en el que despliega una crítica policial ${ }^{8}$ del Hamlet de Shakespeare. Bayard Ilama "sordera" a la dificultad de comunicación entre los críticos ilustrada por la incesante discusión en torno al sentido de las obras. Algo que la crítica ha advertido particularmente con esta célebre tragedia shakesperiana, lo que ha llevado a Bloom a titular uno de sus últimos libros Hamlet. Poem Unlimited (2003) y a Holland a afirmar: "Si miramos los volúmenes sobre volúmenes de comentarios sobre la tragedia, nos daremos cuenta de que, finalmente, cada persona tiene su propio Hamlet" (1975, p. 28). Frente a esta diversidad que surge en las conversaciones en torno a un libro, Bayard no tarda en preguntarse: ¿estamos leyendo la misma obra?

El crítico francés propone una distinción entre objeto y referente que resulta pertinente para responder esta pregunta:

Entre dos personas que discuten sobre una pieza teatral de Shakespeare el objeto es idéntico, con la sola condición de que estén provistos de una edición parecida. Pero, idéntico, el referente de sus discursos -es decir el mundo virtual poblado de criaturas imaginarias con las que se relacionan- no lo es. Entre el texto como objeto y el texto como referente se interpone la delgada lámina del lenguaje crítico, tejido de lo imaginario, que separa al texto de sí mismo (2002, p. 47).

¿De qué se trata este lenguaje crítico "tejido de lo imaginario" que se involucra en el diálogo de dos personas sobre un objeto textual idéntico?

Por un lado, este lenguaje crítico está atravesado por un contexto específico, el marco particular desde el cual cada lector interpreta un texto. En este sentido -y otra vez en la línea argumental del pensamiento derrideano- las innumerables recontextualizaciones de un texto suponen la imposibilidad de fijar su sentido y ponen a prueba las condiciones de comunicación.

En Bayard además, la noción de "contexto" aparece bajo distintos nombres. Uno de ellos, recuperando una noción de Kuhn (1971), es el de paradigma. Si un paradigma permite una lectura y cierto acuerdo en una comunidad mediante una inmovilización temporal del sentido, también exhibe al mismo tiempo el carácter móvil e inestable del texto. Lo que se advierte por las diferencias entre los Hamlet elaborados en las distintas épocas.

Notable es el caso de la lectura de Hamlet de la comunidad aborigen de los Tiv, en África occidental, relatado por la antropóloga norteamericana Laura Bohannan -y al cual Bayard hace referencia en Comment parler des livres que l'on n'a pas lus ? (2007). La antropóloga se encuentra un día leyendo en su cabaña Hamlet de Shakespeare, y un grupo de Tiv, intrigado por la lectura de la extranjera, le pide que comparta el texto y lea en voz alta la tragedia. Cuando Bohannan comienza la lectura se tropieza con dificultades causadas por la pertenencia a diferentes culturas. Así, los Tiv no pueden concebir la idea de que el difunto rey vuelva para hablar a su hijo, porque los fantasmas no existen en su sistema de creencias. Para uno de los jefes de la comunidad de los Tiv, el espectro del rey es "un signo enviado por un brujo" (Bohannan, 1966, p. 29). La antropóloga insiste en la naturaleza espectral del padre de Hamlet, pero el acuerdo parece imposible. No se trata del único inconveniente, y pronto las diferencias interpretativas generan un diálogo de sordos entre Bohannan y los Tiv sobre aspectos que involucran elementos tan fundamentales en la obra como las relaciones parentales y el tipo de vínculos establecidos.

¿Qué están leyendo los Tiv y Bohannan? Si la respuesta es Hamlet, ante el desacuerdo es necesario volver a insistir: ¿se trata del mismo texto?, ¿leen unos y otros el mismo Hamlet?

$8 \quad$ La "crítica policial" de Bayard consiste en proponer soluciones alternativas a casos policiales de la literatura, señalando que los detectives han cometido equivocaciones, y han dejado libres a los verdaderos asesinos. Esta crítica fue desplegada en una trilogía compuesta por sus libros: Qui a tué Roger Ackroyd? (1998), Enquête sur Hamlet (2002) y L'affaire du chien des Baskerville (2008). Recientemente, en el espíritu irónico que atraviesa esta trilogía, la crítica policial ha dado lugar a un grupo constituido por investigadores de universidades de todos los continentes llamado InterCriPol. 
Esta pregunta ataca la estabilidad del texto. escindido aquí entre objeto y referente. El texto es más el resultado de una interpretación ejercida desde un paradigma determinado que un contenido al que se puede acceder con independencia del marco contextual de referencia. Sin embargo, el paradigma no es un contexto de estabilización del sentido, porque, en cuanto conjunto de preguntas y presupuestos a partir del cual se lee un texto, resulta él mismo objeto de interpretación. Los contextos producen interpretación, pero son también su producto.

En este sentido, el paradigma de Bayard podría ser entendido en relación a la noción de "comunidades interpretativas" de Fish (1980): es decir, un grupo social que comparte un conjunto de supuestos y estrategias interpretativas que "determinan la forma de lo que es leído antes que, como en general se asume, al revés" (1980, p. 171). Pero las comunidades interpretativas no tienen más estabilidad que el texto que producen: son convencionales, son constructos sociales, y están por lo tanto sujetas a una transformación permanente.

Esto supone la negación de un sentido transcontextual del texto, es decir un sentido independiente de su inscripción contextual. Supone también la negación de un contexto fijo y estable a partir del cual establecer un contraste con el texto: "todos los textos son igual y radicalmente huérfanos -dice Fish en una metáfora que parece recuperar de modo crítico el Fedro de Platón- en el sentido de que ninguno de ellos está atado con seguridad a un estado de cosas independientemente especificable" (1982, p. 700). Fish está asumiendo, de esta manera, la posición que Derrida sostenía (1972), donde afirma que "un contexto nunca es absolutamente determinable" y que "nunca está asegurada o saturada su determinación" (p. 369) ${ }^{9}$.

De acuerdo con este razonamiento, Hamlet resulta huérfano en la medida en que ningún fundamento independiente permite su estabilización y la unidad de su sentido: ni la lectura de los Tiv, ni aquella de la antropóloga, ni aún aquella que recurriría al autor Shakespeare. Pero, además, el mismo contexto ofre- cido por los Tiv está sujeto a la interpretación, en este caso de la antropóloga, de la misma manera que el contexto de recepción de ella está sujeto a la interpretación de los Tiv (quienes buscan comprender la lectura de la extranjera interpretando la posibilidad de existencia de los fantasmas).

Así, Hamlet solo existe a partir de una interpretación que emerge desde un paradigma, comunidad o contexto determinado y que es a su vez interpretable, en tanto solo puede ser leído desde otro paradigma. No existe un contexto de permanencia, exhaustivamente determinable que desde un afuera detenga la movilidad del texto; un contexto cuyas claves interpretativas sean legibles para cualquiera independientemente de su posición. Esto es, no existe un contexto que excluya la interpretación.

La comedia de desencuentros comunicativos que relata Bonhanan podría muy bien adjudicarse a la distancia que media entre una antropóloga inglesa y una comunidad de África Occidental. ¿Pero no revelan los volúmenes sobre volúmenes dedicados a Hamlet los desencuentros entre los críticos literarios de una misma comunidad interpretativa? Esta pregunta nos conduce a otra, planteada por Derrida a Gadamer en el coloquio de 1981: “¿Qué pasa con la buena voluntad -la condición para el consenso, incluso en el desacuerdo- si uno quiere integrar una hermenéutica psicoanalítica en una hermenéutica general?" (1989, p. 53).

Vale la pena recordar aquí un experimento que HoIland desarrolló en los años setenta (1975), donde entrevistó a cinco estudiantes de literatura sobre sus lecturas del cuento "A Rose for Emily", de William Faulkner (1897-1962). ¿Con qué se encontró en esas entrevistas? Con la pura diferencia. Cada uno de estos estudiantes -que tienen la misma nacionalidad, pertenecen a la misma clase social y generación, estudian y comparten la misma carrera universitarialee el cuento de Faulkner de un modo completamente distinto al de sus pares. ¿Cómo explica Holland esta diversidad? Utilizando la noción de "identidad" del psicoanalista Heinz Lichtenstein -quien la define como un tema y sus variaciones-, Holland postula la

$9 \quad$ Derrida repite esta idea en "Living On", cuando habla de un enunciado y su relación a un contexto, y luego señala: "El enunciado los sobrevive a priori, sigue viviendo más allá de ellos. Así, ningún contexto es ya saturable. Ninguna inflexión goza de un privilegio absoluto, ningún significado puede ser fijado o determinado. Ningún borde está garantizado, dentro o fuera" (1979, p. 78). Y más adelante: "ningún significado puede ser determinado fuera de contexto, pero ningún contexto permite la saturación (1979, p. 81). 
hipótesis según la cual la recepción literaria involucra la identidad del lector (con sus fantasmas y mecanismos defensivos) que busca recrearse en cada acto de lectura. En palabras de Holland: "Toda lectura se origina en la personalidad del lector (...) O más bien: el lector responde a una obra literaria usándola para recrear sus propios procesos psicológicos característicos. Lo que el lector lee es finalmente, lo que el lector lee" (1975, p. 40).

¿Leen los Tiv y Laura Bohannan el mismo Hamlet? ¿Leen los cinco estudiantes de Holland el mismo cuento de Faulkner? Si lo que el lector lee es lo que el lector lee, ¿cómo es posible comunicarse sobre un objeto en el que no coinciden los referentes?

No lejos de Holland -aunque sí del psicoanálisis del yo al que este último adhiere-, Bayard propone la noción de "paradigma interior", "constituido por un grupo de preguntas personales (y la articulación entre ellas)" que modelan inconscientemente el texto (2002, p. 162). El paradigma interior no solo supone el conjunto de preguntas que se hacen al texto sino también el movimiento mismo por el que el texto, en tanto referente, se constituye. Un movimiento de "incurvación" en el que cada palabra es sustituida por otra idéntica en su significante pero que resulta sin embargo diferente en cuanto reenvía a significaciones personales. El paradigma interior "incurva" el texto; desvía el texto material, inaccesible epistemológicamente, hacia uno interior. Pero este último no es posterior a aquel, porque su constitución es retroactiva, en la medida en que el paradigma mismo construye su referente: "La puesta en acción del paradigma interior se produce en la constitución de la obra como pretexto, es decir en su disociación consigo misma" (2002, p. 162). Esta disociación -que corresponde a la separación entre objeto y referentesupone en consecuencia tanto una mediación entre el texto y el lector -el acceso al texto está mediatizado por el sujeto- como una constitución de la obra literaria. Para decirlo de otro: la mediación es constitutiva; la perturbación fundamenta la comunicación.

Detengámonos aquí un momento y demos lugar a algunas preguntas que merecen atención. ¿Cómo es posible esta "incurvación" del texto? ¿Cómo es posible sustituir una palabra por otra idéntica en su significante pero no en su significado? ¿Cómo es posible que en la interacción entre un texto y un contexto (el paradigma general y el interior) el mismo objeto constituya diferentes referentes?

Ya se ha adelantado la respuesta a estas preguntas al referirnos a la ambigüedad que Empson encontraba en los textos literarios, fundamentalmente la descrita como el séptimo tipo: "ocurre cuando los dos significados de la palabra, los dos valores de la ambigüedad, son dos significados opuestos definidos por el contexto, de tal modo que el efecto total producido muestra una división fundamental en la mente del escritor" (1984, p. 192). De Man por su parte, que ve en Empson un precursor, tiene un nombre específico que conceptualiza este tipo de ambigüedad: la "indecidibilidad". Se trata de una noción que define la perspectiva epistemológica del crítico belga y se fundamenta en una concepción tropológica y no referencial del lenguaje. Para De Man, la literatura es un discurso capaz de exhibir la no coincidencia entre el signo y el objeto: "es la única forma de lenguaje libre de la falacia de la expresión inmediata" (2010, p. 17).

De Man además, se interesa en la retórica como una ciencia de los tropos, y no como un modo de servicio a la gramática. En este sentido, la indecidibilidad emerge precisamente en la tensión producida entre niveles discursivos, "cuando es imposible decidir, mediante mecanismos gramaticales o lingüísticos, cuál de los dos significados (que pueden ser totalmente incompatibles) prevalece" (2010, p. 10). Allegories of Reading consiste en un análisis de obras de autores como Proust, Rilke o Rousseau en los que una lectura atenta (close reading) permite observar momentos en los que el lector se enfrenta a dos sentidos igualmente legítimos pero excluyentes entre sí, de modo tal que se produce una cierta ilegibilidad debida a la contradicción entre niveles de sentidos superpuestos.

Muy cerca de este retoricismo demaniano, Bayard abordará numerosas veces el problema de la indecidibilidad a la que nos enfrentan los textos, a los que define en Qui a tué Roger Ackroyd ? como "máquinas de producir lo indecidible" (1998, p. 79). En Le paradoxe du menteur -al analizar las diversas aporías que atentan contra la unidad de Les liaisons dangereuses de Chorderos de Laclos- entiende la indecidibilidad 
en estos términos: "elementos contradictorios han sido dispuestos en puntos cardinales de la estructura del conjunto, impidiendo que nos hagamos una idea relativamente coherente y unificada del proyecto del texto" (1993, p. 173). No es casual que el tropo preponderante en este ensayo de Bayard sea la silpesis: figura consistente en la posibilidad de leer una palabra en su sentido figurado y literal simultáneamente. Para el crítico francés, la silepsis representa metafóricamente la división del signo y enfrenta al lector a enunciados indecidibles que atentan contra la unidad de la obra y la comunicación de una verdad por adecuación.

Todo acto interpretativo es, así, una decisión sobre un fondo de indecidibilidad. Un acto que supone un cierto grado de violencia en cuanto exige la exclusión de un sentido posible, la ilusión del carácter unitario del signo, de la fijación entre un significante y su significado. Sin embargo, la existencia virtual del otro sentido produce una separación entre el texto como objeto y el texto como referente constituido por la lectura. Entre uno y otro, la comunicación tropieza con una incurvación; como en la refracción, la lectura produce un desvío del objeto hacia el referente.

Ahora bien, el problema no se reduce al acceso al texto, sino que se extiende a la posibilidad del diálogo entre lectores. La noción de "paradigma interior" trae consigo la concepción kuhniana de la inconmensurabilidad de los paradigmas, y con ello el problema de la comunicación. Al respecto, afirma Bayard:

Con la noción de inconmensurabilidad, Kuhn introduce en la reflexión sobre la historia de las ciencias un factor fundamental: la no-comunicación. Esta historia no se organiza por una progresión dialógica en la que dominaría el intercambio razonado de argumentos. Está más bien determinada por el tiempo de una sordera, constitutiva de los intercambios de paradigmas (2002, p. 117).

Del mismo modo, y en un sentido que vendría a cuestionar una hermenéutica concebida como un diálogo armónico entre horizontes, la perspectiva de
Bayard decanta en lo que denomina una hermenéutica privada. Entre una hermenéutica que reivindica la existencia de un sentido único para todos y un relativismo que pregona la inexistencia del sentido, la hermenéutica privada sostiene la existencia del sentido del texto, pero en la singularidad de cada lector. La hermenéutica privada aparece como una operación irónica -en efecto: ¿no es el campo de la hermenéutica el espacio público del diálogo?- que procura cuestionar aquello que Derrida llama -en la pregunta a Gadamer- la hermenéutica general. Al hablar sobre el paradigma interior, el crítico francés escribe una afirmación que define con precisión la diferencia entre una hermenéutica y otra: la privada "no supone un texto modificado por las variaciones de subjetividad -en cuyo caso el diálogo podría tener como objetivo acercar cada texto singular a ese texto general-; plantea la hipótesis de una heterogeneidad de estructura entre los textos, que no son anteriores a los críticos, sino producto de ellos" (2002, p. 163).

Todo diálogo crítico es un diálogo de sordos en la medida en que se asienta sobre un equívoco: la creencia de estar hablando del mismo referente. Incluyendo al psicoanálisis en la reflexión sobre la comunicación literaria, Bayard da cuenta de la dificultad epistemológica que ya la hermenéutica gadameriana advertía al identificar los horizontes que se encuentran en el acto de lectura.

Sin embargo, a diferencia de Gadamer -y en consonancia con Derrida-, Bayard se interesa menos por la conciliación que por la diferencia. No se trata solo de señalar la insalvable distancia que me separa del otro -Gadamer es lo suficientemente cauto como para no sucumbir ante la creencia de un posible sueño de la comunicación total: se trata de reivindicar la diferencia, de pensar una ética de la comunicación literaria que da lugar a la inscripción del sujeto y su deseo:

En un pensamiento psicoanalítico del texto, el referente es menos el texto que el objeto del deseo. Todo el trabajo artificial de la puesta en común del pensamiento apunta entonces a protegerse de la amenaza de este objeto, disimulando (...) la imposibilidad del diálogo crítico, cuyo principio es incluso 
contradictorio con las ideas de deseo y de inconsciente (Bayard, 2014, p. 180) ${ }^{10}$.

Reverso de la hospitalidad del diálogo ininterrumpido -aquella doble y paradójica que implica el alojamiento del otro en su alteridad incomprensible y el deseo de no ser comprendido-, la hospitalidad del diálogo de sordos es la que ofrece el texto al lector como posibilidad de inscribir su lengua particular y su deseo. Como señala De Man en una expresión que hemos evocado más arriba: "ya no es una cuestión de imitación sino de creación; ya no de comunicación sino de participación" (De Man, 2010) ${ }^{11}$.

\section{DE LA (IN)COMUNICACIÓN A LA PARTICIPACIÓN}

Para ser franco, el crítico debería decir: Señores, voy a hablar de mí a propósito de Shakespeare, de Racine, de Pascal, o de Goethe. Son una bella ocasión.

\section{Anatole France}

¿Qué consecuencias se perfilan para la crítica en este recorrido que va del sueño de la comunicación de Richards, pasando por el diálogo ininterrumpido (que surge del cruce entre la hermenéutica y al deconstrucción) al diálogo de sordos de Bayard (que surge del cruce entre la hermenéutica y el psicoanálisis)?

Los cuatro fragmentos de Anatole France que hemos citado como epígrafe en los apartados que constituyen el cuerpo de este ensayo pertenecen a un mismo párrafo del prefacio a La vie littéraire (1924, p. iv): suerte de fundamentación a la crítica impresionista. Por una curiosa vuelta, estas palabras que fundamentan la crítica impresionista contra la cual reaccionó Richards y el New Criticism posterior -por motivos, es cierto, no solo vinculados a un cierto cientificis- mo sino también a una oposición al dogmatismo profesoral de los departamentos de letras en Estados Unidos- esbozan ya el recorrido problemático que desplegamos en este artículo y permiten pensar la comunicación literaria y sus consecuencias para la crítica desde la deconstrucción y el psicoanálisis. En cierto modo, podría decirse que este artículo ha sido un largo comentario a ese fragmento que hemos dividido en cuatro partes. Volvamos, pues, a él.

France sueña con una experiencia de comunión absoluta con el otro. Con una otredad radicalmente situada aquí en dos "otros" que han interesado especialmente a la deconstrucción y al psicoanálisis respectivamente: la animalidad (la mosca, el orangután); el otro sexo (que solo Tiresias conoce). Pero eso nos está prohibido. No podemos comprender la naturaleza con el cerebro de un orangután; no podemos, como Tiresias, acordarnos del otro sexo que hemos sido. France expresa así la doble mediatización que afecta la comunicación y es constitutiva del sujeto: el lenguaje; la sexualidad. Mediatización que lleva a un fatalismo resignado, prisión perpetua de la que no podemos salir y en la cual al hablar del arte no hacemos otra cosa que hablar de nosotros mismos. Shakespeare se convierte entonces en una bella ocasión para este decir de sí mismo, para este diálogo de sordos en el que, para emplear una expresión de Oscar Wilde, hay tantos Hamlet como melancolías.

En tal posición, acecha siempre la amenaza de solipsismo: "¿Hay realmente un discours de l'autre o solo un monólogo interrumpido?", pregunta Geoffrey Hartman (1975, p. 34) ante el prefacio de Anatole France. En esta pregunta parecen encontrarse las dos problemáticas que atraviesan la comunicación desde los dos ángulos con que la hemos analizado: aquella que se vincula a la hospitalidad del diálogo

10 Ricoeur también introdujo el psicoanálisis en la hermenéutica, distanciándose así del antisubjetivismo y antipsicologismo de Heidegger y Gadamer. El interés por el sujeto de la lectura -como en Bayard-conduce a Ricoeur a pensar la refiguración como un proceso en el que el lector, frente al texto, aumenta la comprensión de sí mismo: "Comprender es comprenderse a sí mismo. Ni imponer al texto la propia capacidad finita de comprender, sino exponerse al texto y recibir de él un yo más vasto" (2001, p. 108). Sin embargo, existen notables diferencias entre Ricoeur y Bayard. Por un lado, este último está más interesado en el modo en que el lector falla en el intento de narrarse a sí mismo a través del texto. Por otro lado, si bien ambos parecen configurar una hermenéutica que se interesa por la estructura del texto y su alteridad, Ricoeur se dirige al estructuralismo para buscar la explicación que permita superar la huerfanidad de la obra escrita y llegar a la comprensión, mientras que Bayard se dirige a la deconstrucción para ponderar la diferencia que habita todo texto, dificulta su comunicación y produce un relanzamiento del sentido.

11 Vale la pena aclarar que esta separación entre mímesis y creación no es tal en un pensador como Ricoeur, quien al hablar de la mímesis en Aristóteles la considera como imitación a la vez que como representación de acción y disposición de los hechos. Para dar cuenta de este uso del término, Ricoeur llega incluso a acuñar la expresión "imitación creadora" (1987, p. 106). En el presente artículo, sin embargo, como el lector habrá ya podido advertirlo, consideramos la imitación (mímesis) como un término distinto al de creación (poiesis), homologando el primero de ellos al sueño de una comunión de las mentes en el sentido de Richards. 
ininterrumpido; aquella que está ligada a la hospitalidad del diálogo de sordos.

Una respuesta probable a la pregunta de Hartman pueda quizás encontrarse en uno de sus colegas de Yale: Harold Bloom. Al hablar de la influencia de una mente en sí misma y de la obra en su autor, el crítico norteamericano se interesa en lo que llama "autoinfluencia": "tal como yo utilizo este término, no es lo mismo que la autorreflexión o la autorreferencia, ni tampoco sugiere narcisismo o solipsismo. Es una forma sublime de ser dueño de ti mismo" (2011, p. 4950). ¿Será la autoinfluencia constitutiva de la comunicación? ¿Será ella un modo de articulación entre el discurso del otro y el monólogo interrumpido? Sin embargo, después de todo: ¿qué sería este monólogo interrumpido?; ¿interrumpe la obra el discurrir monológico del lector?; ¿interrumpe a su vez el lector el discurso del otro, en su alteridad radical, atravesando con la interpretación lo que de irreductible e incomprensible se encuentra en él? Lo uno y lo otro: diálogo ininterrumpido y diálogo de sordos son metáforas que procuran explicar la paradójica relación comunicativa entre el lector y el texto, allí donde la incomunicación es fundamento y posibilidad del diálogo, espacio de la escucha de una alteridad radical y espacio de inscripción del sujeto de la lectura.

Para Bloom, todo poema -y también toda crítica, que no es para él sino una forma de literatura- "es una comunicación deliberadamente retorcida, vuelta al revés. Es una traducción equívoca (mistranslation) de sus precursores" (1997, p. 71). La teoría poética de Bloom introduce el equívoco (misprision) como el motor de la historia literaria. La imposibilidad de la comunicación transparente es la condición de posibilidad de la crítica, en el sentido en que el equívoco no es accidente sino esencia de la comunicación. En otras palabras, hay crítica porque hay equívoco. De allí la expresión de equívoco creativo (creative misprision) o equívoco poético (poetic misprision) que Bloom (1997) utiliza para pensar las relaciones de influencias de la historia de la literatura. El equívoco se conjuga en la bisagra que articula el discurso del otro y el monólogo interrumpido, que transita de la deslectura (misreading) a la escritura, de la crítica a la literatura: "Como la crítica -dice Bloom-que es parte de la literatura o nada, la gran escritura es siempre el producto de una deslectura (misreading) fuerte (o débil) previa a la escritura" (1997, p. xix).

Es en este marco que podemos comprender el modo en que el diálogo de sordos que propone Bayard deviene en lo que llama "crítica intervencionista": proyecto que despliega desde Le paradoxe du menteur en adelante. Se trata de una crítica que cuestiona los límites que la separan de la literatura y que se propone escribir los textos posibles que existen virtualmente en un texto: L'affaire du chein des Baskerville (2008) reescribe una novela de Sherlock Holmes para demostrar que el detective se ha equivocado dejando al asesino suelto; Et si les œuvres chaneaient d'auteur? (2010) pone a prueba el juego borgeano de reatribuir las obras a otros autores y transformarlas mediante una reescritura interpretativa; Aurais-je sauvé Génévieve Dixmer? (2015) arriesga una reescritura que sigue la fantasía bayardiana de salvar a la heroína que muere en la novela de Dumas.

De la incomunicación a la participación: la crítica intervencionista es la escritura de una de las posibilidades del texto cuyo significado está en constante vuelo. La historia de la literatura es pensada desde entonces como una serie ininterrumpida de fallas comunicativas que dan lugar a procesos de intervención: "la recepción de una obra singular -afirman dos autores cercanos a Bayard- se confunde con la serie de malentendidos a los que da lugar, [en tanto] que tal es incluso la condición de la renovación constante del significado" (Clément y Escola, 2002, p. 6). Para agregar inmediatamente: "No hay lectura sin malentendido".

\section{CONCLUSIÓN}

Esa vista infunde fortaleza a los ángeles, puesto que ninguno puede comprenderte, y todas tus obras excelsas son magníficas, como el primer día.

J. W Goethe, Fausto

Evocando al Doktor Faustus de Thomas Mann, Mijaíl Bajtín imaginaba el infierno como "una situación en la que uno no es escuchado por nadie" (2011, p. 315). ¿Será ese infierno el que Anatole France estaba describiendo al referirse a la "prisión perpetua" y a la "espantosa condición" de no hablar más que con 
nosotros mismos cuando no tenemos la fuerza de callarnos? No lo creo. Las figuras que aparecen detrás de la prisión perpetua parecen ser las mismas que emplea Bayard con el diálogo de sordos: la hipérbole y la ironía.

Ni Anatole France ni Pierre Bayard ni Jacques Derrida -de acuerdo al recorrido interpretativo que hemos llevado a cabo- indican que la comunicación no existe. Las figuras que despliegan apuntan a subvertir la posición de una comunicación transparente y revertir irónicamente el sueño de la comunión de un contenido mental. Incluso cuando Derrida pregona una hospitalidad basada en el alojamiento y la escucha atenta del otro, lo que se reivindica allí no es la comprensión del otro sino la experiencia de la diferencia irreductible que lo separa de la propia. El respeto por el texto no conduce a su comprensión, sino a la suspensión de todo intento comprensivo. Tal es la razón por la cual, en el Fausto de Goethe, los ángeles vinculan la eterna actualidad de las obras de Dios, magníficas como el primer día, a la incapacidad de comprenderlo. "Puesto que nadie puede comprenderte" -dicen los ángeles ${ }^{12}$.

France, Derrida y Bayard reclaman, por así decirlo, un sueño de la incomunicación y la participación. Hemos recorrido en este ensayo los motivos epistemológicos que fundamentan este sueño, según el cual el ruido, la perturbación, el malentendido, no son "un accidente de la comunicación, sino su esencia". Tal recorrido nos ha permitido ver dos tipos de perturbaciones que configuran el accidente de la comunicación: una vinculada al texto; otra al lector.

La primera de ellas se vincula a las aporías que surgen como consecuencia de las ambigüedades y de las tensiones entre la retórica y la gramática. El propio Bayard subraya en diversas ocasiones la indecidibilidad a la que se enfrenta la lectura de los textos literarios. La naturaleza retórica del lenguaje vuelve al intérprete incapaz de decidirse por un sentido unívoco de un enunciado sin encontrar simultáneamente otro que lo excluya. Como en la séptima ambigüedad descrita por Empson, un texto comunica un sentido y otra a la vez, dando lugar a un malentendido inevitable. Tal perturbación se liga a lo que hemos llamado "la hospitalidad del diálogo interrumpido", es decir el alojamiento de la alteridad incomprensible del texto en el acto de recepción.

La segunda de las perturbaciones remite a las fricciones que se producen entre el texto y el contexto por la distancia que los separa. Esto nos ha conducido a analizar la noción de paradigma como contexto mediador entre el texto y el lector, así como a considerar la implicancia del lector como sujeto del inconsciente. Tal perturbación está vinculada con lo que hemos llamado "la hospitalidad del diálogo de sordos", es decir la inscripción del lector en la experiencia comunicativa.

Atentos a las razones epistemológicas que median el acto comunicativo, la reivindicación de la incomunicación denuncia la violencia interpretativa que se oculta detrás de la ambiciosa comunión de la experiencia literaria. Pero simultáneamente, el sueño de la incomunicación piensa la lectura como un acto hospitalario no solo respecto al lector sino también respecto al texto.

La imposibilidad del sueño de la comunicación no significa que la comunicación no ocurra: al contrario, el equívoco es la condición de la lectura, la posibilidad del relanzamiento del sentido, el fundamento infinito del diálogo. El diálogo ininterrumpido y el diálogo de sordos -con sus respectivos modos de hospitalidad señaladas- remiten a una comunicación que concibe a la crítica como un pasaje de la lectura a la escritura, de la imitación a la participación.

Hay comunicación por el trasfondo epistemológico de su imposibilidad. Paradoja que nutre el devenir de la crítica. "Más que ninguna otra obra de Shakespeare (o de cualquier otro autor), Hamlet es una incesante provocación al mundo, porque el mundo encontró en ella un misterio irresoluble" (Bloom, 1997, p. 48). A diferencia de Bajtín, en estos apólogos de la incomunicación el infierno es la transparencia del sentido, la comunión con el otro que afecta la diferencia e inhibe el poder inagotable del misterio, verdadero privilegio de la literatura. 
Problemas de la comunicación literaria. Del sueño de la comunicación al diálogo de sordos

\section{REFERENCIAS BIBLIOGRÁFICAS}

Bajtín, M. (2011). Estética de la creación verbal. Buenos Aires: Siglo XXI.

Bayard, P. (1993). Le paradoxe du menteur. Sur Laclos. Paris: Minuit.

Bayard, P. (1998). Qui a tué Roger Ackroyd ? Paris: Minuit.

Bayard, P. (2002). Enquête sur Hamlet. Le dialogue de sourds. Paris: Minuit.

Bayard, P. (2007). Comment parler des livres que l'on n'a pas lus ? Paris: Minuit.

Bayard, P. (2008). L'Affaire du Chien des Baskerville. Paris: Minuit.

Bayard, P. (2010). Et si les œuvres changeaient d'auteur? Paris: Minuit.

Bayard, P. (2015). Aurais-je sauvé Geneviève Dixmer ? Paris: Minuit.

Bloom, H. (1997). The Anxiety of Influence. Oxford: Oxford University Press.

Bloom, H. (2003). Hamlet. Poem Unlimited. Nueva York: Riverhead Books.

Bloom, H. (2011). Anatomía de la influencia. Buenos Aires: Taurus.

Bohannan, L. y Bohannan, P. (1966). A source notebook in Tiv history and political organization. EE.UU.: Human Relations Area Files.

Bohannan, L. (2009). Shakespeare in the Bush. Natural History, 75, 28-33.

Clément, B. y Escola, M. (2002). Le malentendu. Saint-Dennis: PUV.

De Man, P. (2010). The Dead-End of Formalist Criticism. En: Blindness and Insight (pp. 229-245). Minneapolis: University of Minnesota Press.

Derrida, J. (1972). Signature événement contexte. En Marges de la philosophie (pp. 365-393). Paris: Minuit.
Derrida, J. (1979). Living On Border Lines. En Bloom, H. (Comp.), Deconstruction and Criticism (pp. 75-176). London: Routledge \& Keagan Paul Ltd.

Derrida, J. (1989). Three Questions to Hans-Georg Gadamer. En Michelfelder, D. \& Palmer, R. (eds.), Dialogue \& Deconstruction (pp. 52-57). New York: SUNY Press.

Derrida, J. (1997). La diseminación. Madrid: Fundamentos.

Derrida, J. (2003). Carneros. El diálogo ininterrumpido. Buenos Aires: Amorrortu.

Derrida, J. y Ferraris, M. (2010). El gusto del secreto. Buenos Aires: Amorrortu.

Descartes, R. (1987). Discours de la méthode. Paris: Librairie Philosophique J. Vrin.

Eco, U. (1992). Obra abierta. Buenos Aires: PlanetaAgostini.

Empson, W. (1984). Seven Types of Ambiguity. London: The Hogarth Press.

Fish, S. (1980). Is There a Text in This Class? Massachusetts: Harvard University Press.

Fish, S. (1982). With the Compliments of the Author: Reflections on Austin and Derrida. Critical Inquiry, 8, 4, 693-721.

France, A. (1924). La vie littéraire. Vol. I. Paris: Calmann-Lévy.

Freud, S. (1992). Lo ominoso. En: Obras completas, XVII. Buenos Aires: Amorrortu.

Gadamer, H. G. (2004). Verdad y método. Salamanca: Sígueme.

Gadamer, H. G. (1989). Text and Interpretation. En Michelfelder, D. \& Palmer, R. (Eds.), Dialogue \& Deconstruction (pp. 21-51). New York: SUNY Press.

Habermas, J. (1981). Teoría de la acción comunicativa. Madrid: Taurus.

Hartman, G. (1975). The Fate of Reading and Other Essays. Chicago: UCP. 
Hartman, G. (1981). Saving the Text. Baltimore: The Johns Hopkins University Press.

Heidegger, M. (2009). El ser y el tiempo. México: FCE.

Holland, N. (1975). 5 Readers Reading. New Haven and London: Yale University Press.

Iser, W. (1987). El acto de leer. Teoría del efecto estético. Madrid: Taurus.

Jakobson, R. (1960). Ensayos de lingüística general. Barcelona: Planeta.

Jauss, H.-R. (1987). El lector como instancia de una nueva historia de la literatura. En: Mayoral, J.A. (Comp.) Estética de la recepción (pp. 59-86). Madrid: Arco/Libros.

Kluge, F. (1957) Etymologisches Wörterbuch der Deutschen Sprache. Berlin: De Gruyter.

Kuhn, T. (1971). La estructura de las revoluciones científicas. México: FCE.
Platón (1955). Fedro o de la belleza. En: Diálogos escogidos. Buenos Aires: El Ateneo.

Poe, E. A. (2007). The Murders in the Rue Morgue. New York: Random House.

Richards, I. A. (1976). Principles of Literary Criticism. London: Routledge.

Ricoeur, P. (1995). Teoría de la interpretación. México: Siglo XXI.

Ricoeur, P. (2001). Del texto a la acción. Buenos Aires: FCE.

Ricoeur, P. (2004). Tiempo y narración I. México: Siglo XXI.

Ricoeur, P. (2009). Tiempo y narración III. México: Siglo XXI.

Vidarte, P. (2006). ¿Qué es leer? La invención del texto en filosofía. Valencia: Tirant lo Blanch. 